\title{
Why Only People and Apes are Ill with Common Cold? The Possible Role of Chromosomal Q-Heterochromatin Variability
}

\author{
Ibraimov A. I. ${ }^{1}$ \\ ${ }^{1}$ Institute of Balneology and Physiotherapy, Bishkek and Laboratory of Human Genetics, National Center of \\ Cardiology and Internal Medicine, Bishkek, Kyrgyzstan \\ Correspondence: Ibraimov A. I., Laboratory of Human Genetics, National Center of Cardiology and Internal \\ Medicine, Bishkek, Kyrgyzstan. E-mail: ibraimov_abyt@mail.ru
}

\author{
Received: December 20, 2015 Accepted: December 27, 2015 Online Published: January 5, 2016 \\ doi:10.5539/jmbr.v6n1p11 URL: http://dx.doi.org/10.5539/jmbr.v6n1p11
}

\begin{abstract}
Common cold (CC) is referred to the most widespread human illnesses and affects people all over the globe. Till now there is no standard theory explaining the development mechanism(s) of CC. The etiology of the CC is known - over 200 virus strains are implicated in the cause of the common cold; the rhinoviruses are the most common. As for pathogenesis, it is conventional, that cold plays the important role in development of CC. It is believed that cooling causes blood circulatory disturbance and permeability of vessels that consequently deteriorates the tissue nutrition and its resistance against infectious agents, and its resistibility in relation to infection. It is also known that the CC sickness rate is affected by the age (children get sick more often than adults) and gender (male individuals are more susceptible to CC than females, regardless of their age). Among the issues that have not received an answer is another question: why CC affects only upon humans and apes? It is hypothesized that the cause of these higher primates susceptibility to CC is the highest level of their body heat conductivity in the animal world. Just this circumstance contributes to the rapid and deep cooling of the bodies of people and apes when it is cold, with all the ensuing negative consequences for the organism.
\end{abstract}

Keywords: common cold, common cold in apes, chromosomal Q-heterochromatin, human body heat conductivity, susceptibility to common cold

\section{Introduction}

Common cold (CC) is the most common infectious human disease in the developed countries, in an average an adult suffers from cold at least 2-3 times a year, a child - 6-10 times a year. Susceptibility to disease is universal and high. The economic impact of the common cold is not well understood in much of the world (Eccles \& Veber, 2009). In the United States, the common cold leads to $75-100$ million physician visits annually at a conservative cost estimate of \$7.7 billion per year. An estimated 22-189 million school days are missed annually due to a cold. As a result, parents missed 126 million workdays to stay home to care for their children. When added to the 150 million workdays missed by employees suffering from a cold, the total economic impact of cold-related work loss exceeds $\$ 20$ billion per year (Fendrick et al., 2003; Eccles, 2005).

$\mathrm{CC}$ is a viral infectious disease of the upper respiratory tract which primarily affects the nose and of the upper respiratory tract. In total over 200 different viral types are associated with colds. Exposure to cold has often been associated with increased incidence of CC. The data available suggest that exposure to cold increases the risk of developing upper respiratory tract infections; in addition, the longer the duration of exposure the higher the risk of infection. Although not all studies agree, most of the available evidence from laboratory and clinical studies suggests that inhaled cold air, cooling of the body surface and cold stress induced by lowering the core body temperature cause pathophysiological responses such as vasoconstriction in the respiratory tract mucosa and suppression of immune responses, which are responsible for increased susceptibility to infections. Lines of evidence regarding the association between exposure to cold and the incidence and severity of respiratory tract infections: 1) clinical evidence (periods of low environmental temperatures lead to an increase in the incidence of respiratory tract infections); 2) experimental evidence (acute chilling of the feet can cause the onset of common cold symptoms within 4-5 days); and 3) pathophysiological evidences (cooling of the nasal airways compromises local defense and cooling of the body surface causes reflex vasoconstriction in the upper airway 
epithelium, leading to reduction in the supply of leukocytes) (see more: Eccles, 2005; Mourtzoukou \& Falagas, 2007).

\section{Common Cold - Background Information}

It should be mentioned at once that for many years the medical science studies the initiation mechanism of common colds (CC). Yet, much remains unclear. So far there is not commonly accepted theory explaining the mechanism of CC development.

But generally the reasons for the $\mathrm{CC}$ development are more or less clear. Its etiology is known - for over 200 virus strains are implicated in the cause of the CC; the rhinoviruses are the most common. Regarding the pathogenesis it is generally accepted that the cold plays an important role in the development of CC. It is known that cooling causes circulatory disturbance and reduces vascular permeability. Changes in blood flow decreased vascular permeability cause malnutrition of tissue and lowering its resistance against the infectious agents. The breathing passages, especially the upper respiratory tract are the reservoir - the home of enormous quantity of microorganisms. These microbes are with the human body in the state of neutrality, but under certain circumstances, they can cause disease. Under certain circumstances, usually it is meant that in upper respiratory tract there are hypothermia and circulatory disturbance of the mucous membranes. The result is a decrease in the concentration of protective substances, a violation of physical and chemical characteristics of mucus, the reduction in the mucociliary activity and, eventually, activation of conditionally pathogenic microorganisms.

The relationship issue of colds and infections is of fundamental and practical importance, but, unfortunately, currently cannot be considered finally clarified. It is accepted generally that the cold plays an important role in the development of a number of infectious diseases. In this connection the important question raises whether the common cold exists as a separate disease (without infection). On this issue, there is no single point of view. Some authors believe that the cold can only predispose to the development of infectious diseases and that without infection it cannot cause disease. Other researchers believe that common cold not only predisposes to the development of a number of infectious diseases, but can cause independently a "respiratory disease" (see more: Eccles, 2005; Mourtzoukou \& Falagas, 2007).

Pathophysiological mechanisms of $\mathrm{CC}$ have been studied generally. In the initial period of the disease the virus replicates in the input "gates of infection": the nose, nasopharynx, and larynx. The virus then enters the bloodstream and causes the symptoms of general intoxication: fever, headache, aching back and limbs. The immune response activation results in development by an organism of antibodies to the virus, whereby the blood is cleaned from it gradually and the symptoms of intoxication diminish. At the final stage of the uncomplicated CC the respiratory tracts are cleansed from infected layers of epithelium, which responses as rhinitis and productive cough with expectoration of mucous or purulent sputum (Eccles, 2005).

Whether the development of respiratory infections is influenced by the exposure of body surfaces to cold (such as exposure of the feet to cold water or surfaces) is controversial. Some studies support that acute cooling of the body surface is responsible for the onset of respiratory infections. In a case-control study, Johnson and Eccles (2005) showed that acute chilling of the feet caused the onset of common cold symptoms in the 4-5 days following the chill procedure in $26 / 90$ case subjects, compared to $8 / 90$ control subjects $(\mathrm{P}<0.001)$.

The effect of cooling of the nasal airway on the susceptibility to respiratory tract infections was analyzed by Eccles (2002a). It is proved that exposure of the upper airways to cold air compromises local defense and therefore increases the incidence of upper respiratory tract infections. The author suggests that the inspiration of cold air causes a decrease in the temperature of the respiratory epithelium. The latter is responsible for the decrease of mucociliary clearance and the local immune responses of the airway, i.e., it compromises phagocytic activity leading to increased susceptibility to infection. It is stressed that the epidemics of respiratory tract infections after a short period of cold weather may be explained by the conversion of asymptomatic clinical infections into symptomatic infections. Eccles in the other work points out that the reflex vasoconstriction in the nose and upper airway epithelium caused by the cooling of the body surface, which has been found to be more prolonged in people who are prone to upper respiratory infections (those who experience many episodes in colds each year), is responsible for the onset of common cold symptoms because of the reduction in blood flow and supply of leukocytes it induces (Eccles, 2002b).

Under normal circumstances, the human body adjusts physiologically to exposure to cold by increased shivering thermogenesis and increased peripheral vasoconstriction to maintain the core body temperature. On the other hand, there is some evidence that the immune system also responds to cold stress. Polderman (2004) supports the immunocompromizing effects of therapeutic hypothermia. He argues that the drop in the core body temperature causes leukocytopenia, suppression of chemotactic migration of leukocytes, suppression of phagocytosis, 
reduction of the release of cytokines, insulin resistance and hyperglycemia, factors that increase susceptibility to infections.

Mourtzoukou and Falagas (2007) think that additional studies are needed to clarify the relationship between exposure to cold and respiratory tract infections. The focus should probably be on clinical research studies using analytical methodology to provide support for or to refute the association between exposure to cold and respiratory tract infections. Appropriately, designed and powered population (community) based randomized controlled trials and case control studies may shed more light on this issue. If the association between exposure to cold and increased incidence and/or severity of respiratory tract infections is found to be adequately supported, relevant guidelines regarding preventive measures should be generated, published and applied as public health practices.

The data available suggest that exposure of the body surface or the upper airways to cold temperatures may contribute to the development of upper respiratory tract infections. The inhalation of cold air or cooling of a part of the body surface is associated with an increased risk of respiratory infections. However, it is evident that only a proportion of the people who are exposed to cold will develop an infection, and this finding suggests that there are other underlying factors that may reduce resistance to infections. Animal studies have also shown that low environmental temperatures affect the severity of experimentally produced infections (Yoder et al., 1977).

In the light of the foregoing, it can be argued that the question remains outside the field of view of researchers: why $\mathrm{CC}$ affects only humans and apes? The fact that man and apes are reputed to be the only susceptible hosts to this disease. Easily managed laboratory animals such as rats, mice, rabbits, cats and dogs are said not to catch the disease, thus making laboratory studies very difficult (Eccles \& Veber, 2009). It is assumed that the species that can catch colds, man and the apes, are the two that cannot make their own ascorbic acid. In this case, can we be confident that the issue has been exhausted? To justify our interest in this issue - why CC affects only humans and apes - it is necessary to apply to the field of knowledge, which, at first view, seems far from rhinology.

\section{Chromosomal Q-heterochromatin polymorphism.}

A fundamental feature of chromosomes in higher eukaryotes, including man, is the presence of two evolutionally consolidated types of genetic material: euchromatin and heterochromatin. Euchromatin, the conservative portion of the genome, contains transcribed structural genes, while heterochromatin, the variable portion of the genome, is predominantly composed of non-coding repeated DNA sequences.

Heterochromatin is universally distributed in the chromosomes of all the eukaryotes - plants, animals and man, accounting for $10 \%$ to $60 \%$ of their genome. Heterochromatin regions (HRs) account for about $15 \%-20 \%$ of the human genome. Chromosomal HRs does not change during ontogenesis and are inherited in a regular manner as discrete traits.

To-date two types of heterochromatin are recognized: Q- and C- heterochromatin (Caspersson et al., 1970; Arrighiand Hsu, 1971; Paris Conference, 1971; Suppl., 1975; ISCN, 1978). There are several significant differences between them: C-heterochromatin is found in the chromosomes of all the higher eukaryotes, while Q-heterochromatin - only in man (Homo sapiens), the chimpanzee (Pan troglodytes) and gorilla (Gorilla gorilla) (Pearson, 1973, 1977; Seuanez et al., 1976).

Q-heterochromatin regions(Q-HRs) variability can be found in man on only seven autosomes $(3,4,13,14,15$, 21 and 22), as well as on chromosome Y. Chimpanzees have Q-variants on five autosomes (14, 15, 17, 22 and $23)$, while in gorillas they are present on eight $(3,12,13,14,15,16,22$ and 23) and on chromosome $Y$ (Paris Conference, 1971; Suppl., 1975; Chiarelliand Lin, 1972; de Grouchi et al., 1973; Seuanez et al., 1976; Pearson, 1977; ISCN, 1978).

Chromosomal Q-HRs are subject to considerably greater quantitative variability in any population. Individuals differ in the number, size, and intensity of fluorescence of these specific chromosomal regions (Paris Conference, 1971; Suppl., 1975; McKenzie \& Lubs, 1975; Müller et al., 1975).

Despite the fact that in the human karyotype there are 25 loci in which Q-HRs can be detected, i.e., there could theoretically exist individuals with 25 Q-HRs in their genome, but such cases have not as yet been reported. In individuals of a population the number of Q-HRs usually ranges from 0 to 10 (Yamada \& Hasegawa, 1978; Al-Nassar et al., 1981; Ibraimov, 2015; Ibraimov \& Mirrakhimov, 1985).

No data are available on the mean number of Q-HRs in natural chimpanzee and gorilla populations. However, the bulk of data in literature suggests that the genome of the gorilla and chimpanzee contains the greatest number of Q-HRs, while that of man - the smallest. It must be noted that such brilliantly fluorescing chromosomal segments are absent in the orangutan (Seuanez, 1979; Seuanez et al., 1976). 
Quantitative variability of chromosomal Q-HRs in human populations has been studied in detail. Some quantity regularities in distribution of chromosomal Q- heterochromatin in population are determined. In particular it is defined that: 1) consistent interpopulation differences in the quantitative content of Q-HRs in their genome were established; 2) these differences proved to be related to features of the ecological environment of the place of permanent residence, and not to racial and ethnic composition of the population; 3) changes in the amount of Q-HRs in the population genome tend to decrease from southern geographical latitudes to northern ones, and from low-altitude to high-altitude ones; 4) the Q-heterochromatin on the Y chromosome is the largest in the human karyotype, and its average size is twice greater than all the Q-HRs on autosomes taken together, so the overall amount of Q-HRs in females is as rule lower than in males; 5) males in the population differ from each other in the size of the Q-heterochromatin segment of the $\mathrm{Y}$ chromosome; 6) in individuals of a population the number of Q-HRs usually ranges from 0 to 10;7) different age groups have different numbers of Q-HRs, the greatest number of Q-HRs is characteristic of neonates, while the lowest - of elderly subjects; 8) in the first days, weeks, months and years of life, ceteris paribus, among healthy children the infants often die with the greatest number of Q-HR in genome; 9) individuals capable of successfully adapting themselves to the extreme high-altitude climate (e.g. mountaineers) and of the Far North (e.g. oil industry workers of polar Eastern Siberia) are characterized by extremely low amounts of Q-HRs in their genome; 10) individuals with a lower amount of Q-HR in their genome proved to be prone to alcoholism and obesity, while those with a greater amount of Q-HR - to drug addiction (for more details see: Geraedts \& Pearson, 1974; McKenzie \& Lubs, 1975; Müller et al., 1975; Buckton et al., 1976; Lubs et al., 1977; Al-Nassar et al., 1981; Stanyon et al., 1988; Ibraimov, 2015; Ibraimov \& Mirrakhimov, 1982 a,b,c;1985; Ibraimov \& Karagulova, 2006a,b; Ibraimov et al., 1982, 1986, 1990, 1991, 1997, 2013, 2014a,b; Kalz et al., 2005; Decsey et al., 2006).

It is notable, that these regularities turned out to be related to the wide human body heat conductivity (BHC) variability in population. To be exact, apparently, human BHC depends mainly on the amount of chromosomal Q- heterochromatin in his genome. As the amount of chromosomal heterochromatin does not change in ontogenesis, it is possible that the level of BHC may be a constitutional character, the same as the color of skin, eye shape, body constitution, height and other innate physical human peculiarities (Ibraimov, 2015; Ibraimov et al., 2014a).

\section{Existing hypotheses}

Present scientific opinion dismisses any cause-and-effect relationship between acute cooling of the body surface and common cold (see above). Thus, for example, Eccles (2002a) proposes a hypothesis that acute cooling of the body surface causes reflex vasoconstriction in the nose and upper airways, and that this vasoconstrictor response may inhibit respiratory defense and cause the onset of common cold symptoms by converting an asymptomatic subclinical viral infection into a symptomatic clinical infection.

In the other work Eccles (2002b) discusses some of the ideas concerning the seasonality of upper respiratory tract viral infections (URTI) and put forward a new hypothesis for discussion, namely that seasonal exposure to cold air causes an increase in the incidence of URTI due to cooling of the nasal airway. The hypothesis is supported by literature reports demonstrating that inhalation of cold air causes cooling of the nasal epithelium, and that this reduction in nasal temperature is sufficient to inhibit respiratory defenses against infection such as mucociliary clearance and the phagocytic activity of leukocytes.

Although possible explanations for this seasonal variation, such as increased crowding of people and other hosts of microorganisms that promote transmission and changes in relative humidity that affect the viability of different microorganisms, have been suggested, the role of exposure to cold per se in the incidence and severity of respiratory tract infections is not well understood. The widespread common belief that there is a relationship between exposure to cold and development of respiratory infections has stimulated research into clinical and laboratory evidence in support of this assumption and in the pathophysiological pathways that lead to the development of infections (Mourtzoukou \& Falagas, 2007).

Isolated areas of Antarctica, where extremely low temperatures dominate, have often been used for the study of the effects of cold on human health. Much more et al. (1981) reported a remarkably high frequency of virus isolation from and persistence in throat specimens in a group of 20 socially isolated persons (American Antarctic Research Station personnel). A total of 105 routine throat swabs were obtained during the 8.5 months of isolation (six specimens for each participant at intervals throughout this period), 48 of which were positive for Parainfluenza virus. Most of the subjects examined (15/20) were found to harbor a respiratory virus more than once, whereas the majority $(12 / 20)$ were asymptomatic. This persistent virus recovery indicated that the viruses were present for prolonged periods of time in an effective form that could be shed and cause disease. These findings were in 
accordance with the clinical observation that upper respiratory tract infections occurred among station personnel for several months (2-6 months of isolation in the South Pole) (Mourtzoukou \& Falagas, 2007).

Anyway, the existing hypotheses regarding the CC pathogenesis recognize the role of common cold, viruses, constantly living in the upper respiratory tract, age and sex, the overall resistance of the organism and immune status. But none of them specifically dealt with the question of why only humans and apes are susceptible to CC.

\section{Own hypothesis}

We believe that the reason for the CC susceptibility of humans and apes is the presence of chromosomal Q-HRs in their genome, which are absent in other species. Yet not having the necessary in such cases experimental data, we, however, postulate that the presence in addition to C-heterochromatin and Q-heterochromatin in the genome of these three higher primates makes them the owners of the highly heat-conductive bodies in the animal world. It has been established that there is a link between the amount of chromosomal Q-HRs in the genome and the human body heat conductivity level (Ibraimov, 2015; Ibraimov et al., 2014a). Although such link has not been defined regarding apes, it is impossible to exclude completely this possibility. Since individuals in a population differ from each other in their body heat conductivity, the level of which depends on the amount of chromosomal Q-HRs in the genome, we believe that human CC susceptibility and frequency of disease probably is determined on how quickly and deeply his body is cooled under the influence of cold.

\subsection{The Facts, Confirming our Hypothesis.}

1) It is a curious truth that only man and apes suffer from the common cold;

2) Chromosomal Q-heterochromatin is found only in man, the chimpanzee and gorilla, while C-heterochromatin - is found in the chromosomes of all the higher eukaryotes;

3) Curiously enough monkeys, unlike the apes, do not seem to be liable to catch common cold;

4) Individuals in population differ in the number of chromosomal Q-HRs (the number of Q-HRs in human genome usually ranges from 0 to 10 );

5) The Q-HR on the $\mathrm{Y}$ chromosome is the largest in the human karyotype, and its average size is twice greater than all the Q-HRs on autosomes taken together, so the overall amount of Q-HRs in females is as rule lower than in males;

6) Different age groups have different numbers of Q-HRs, the greatest number of Q-HRs is characteristic of neonates, while the lowest - of elderly subjects;

7) Human body heat conductivity level depends mainly on the amount of chromosomal Q-heterochromatin in his genome;

8) Adults typically have two to five infections annually and children may have six to ten colds a year (and up to twelve colds a year for school children), at this, the male individuals are ill more often than the opposite sex representatives.

9) The concept ("Man flu") originated, when many of men suffer from the flu harder than women. Scientific justification is accumulated for the legitimacy existence of the concept of "Man flu" as a more severe form of CC (Alleyne, 2009; MacRae, 2009);

10) And finally, it is evident that only a proportion of the people who are exposed to cold will develop an infection.

\subsection{Interpretation of the facts.}

The existing hypotheses of the $\mathrm{CC}$ pathogenesis does not give a convincing answer - in addition to exceptional susceptibility of people and two species of apes - to the following important questions, why: 1) male individuals more often ill with CC than individuals of the female sex irrespective of their age, living and environment conditions; 2) children get sick with CC more often than adults; 3 ) in the population some individuals are ill with $\mathrm{CC}$ more often than others?

Existing hypotheses link all this, basically, with different resistance of different organisms, the immune status and the level of human material welfare (clothing, living conditions and nutrition). To our point of view these general considerations, at their importance, does not give a convincing answer to the above questions. Thus, for example, if the only people would be CC susceptible, or vice versa, for example, all warm-blooded animals, then one could be fully agree with existing ideas about the CC pathogenesis. However, the fact that CC susceptibility only in people and two of the present three apes (chimpanzee and gorilla, except for orangutan) as well as the importance of gender and age factors, make the problem of the $\mathrm{CC}$ pathogenesis is very intriguing. 
With a view of our hypothesis, these issues could find satisfactory explanation if to put first such factors as the level of the body heat conductivity (BHC). We believe that only a human and two apes, being, having in its genome besides C-heterochromatin an additional Q-heterochromatin, are holders of the highly BHC in the animal world (Ibraimov, 2015; Ibraimov et al., 2014a). Based on this view, it is possible to explain rationally the question put in the present work.

Thus, for example, the greater CC susceptibility of male individuals may explain the relatively higher heat conductivity of their bodies, in comparison with the opposite sex representatives (Ibraimov \& Tabaldiev, 2007; Ibraimov et al., 2010). This is related to a well-known fact that the male karyotype has a Y chromosome that contains the largest block of Q-heterochromatin in the human genome. The existing hypotheses of greater most CC susceptibility of men are explained by the fact that the female body is more resistant, including to infections, and this is a biological strategy to protect the reproductive role of the female body, to keep the human race going. This point could be argued by the fact that; a new survey, by the Office for National Statistics, has found that men in Britain are less likely than women to take time off work due to illness. The survey showed that up to the age of forty men are off work sick for just two percent of their working lives, around half of the rate for women (BBC News (24 March 2010)).

The question why children often ill with $\mathrm{CC}$ than adult individuals in the population can be answered by the fact that different age groups have different numbers of Q-HRs, the greatest number of Q-HRs is characteristic of neonates, while the lowest - of elderly subjects (Buckton et al., 1976; Ibraimov \& Karagulova, 2006; Ibraimov et al., 2014b). As well as it is that, individuals from different age groups in the population differ in the level of their BHC; children have the highest heat conductivity, and the lowest BHC have individuals from older age groups (Ibraimov \& Tabaldiev, 2007; Ibraimov et al., 2010).

Different human CC susceptibility may find their rational explanation in the framework of the understanding of the importance of the level of BHC in maintaining the temperature homeostasis in the human body (Ibraimov, 2015). Individuals in a population vary greatly in the level of their BHC (Ibraimov \& Tabaldiev, 2007; Ibraimov et al., 2010; 2014a). If our hypothesis is correct, then we can expect that individuals with high BHC would be more susceptible to $\mathrm{CC}$ and vice versa. It is the level of human BHC that determines how quickly and deeply his body becomes cool at cold, and ultimately the CC susceptibility of an organism.

\subsection{Experimental Check Ways}

Our hypothesis can be tested experimentally in humans. Ideally it is better to choose a large sampling of only women individuals (the presence of the largest and highest polymorphic Q-heterochromatin in the male genome may interfere with the purity of the experiment) in the reproductive age, working in the same temperature and production conditions (e.g., greenhouses) and to watch (monitor) for a certain period of time for their CC incidence In parallel to determine their BHC level, and even better the amount of chromosomal Q-HRs in their genome (prospective study).

If desired, the human BHC level can be determined outside the laboratory. It's enough to have an ordinary medical thermometer to determine the temperature of the oral cavity and medical pyrometer, non-contact detector of surface temperature of the human body (for details see, Ibraimov et al., 2014a).

The study can be done retrospectively by interviewing individuals from the same sampling, in advance having defined the BHC levels of their bodies and/or the content of chromosomal Q-HRs in the genome. If the results of these studies show a statistically significant link between the level of BHC and the frequency of the CC for at least a year, then this hypothesis may be taken as a basis for further deeper research.

\section{Concluding Remarks}

The question may appear whether the benefits of knowledge, if indeed it is revealed that CC susceptibility of humans and apes really is associated with very high heat conductivity of their bodies? To create vaccines against hundreds of potentially dangerous strains of viruses that live in the human upper respiratory tract is possible, but impractical. Therefore, the efforts of scientists are directed at searching drugs and other agents that can neutralize the harmful effects of these viruses. We believe that knowledge of the different BHC in various individuals within the population may be practically useful in the sense that people knowing about constitutional peculiarities of their bodies (in this case, the level of heat conductivity) will know how vulnerable they are to cold.

\section{References}

Alleyne, R. (2009). Men succumb to man flu because women have stronger immune systems, claim scientists. The Daily Telegraph (Published 12 May 2009). 
Al-Nassar, K. E, Palmer, C. G., Connealy, P. M., \& Pao-Lo, Y. (1981). The genetic structure of the Kuwaiti population. II. The distribution of Q-band chromosomal heteromorphisms. Hum Genet, 57, 423-427.

Arrighi F. E., \& Hsu T. C. (1971). Localization of heterochromatin in human chromosomes. Cytogenetics, 10, 81-86.

BBC. (2010). Women 'take more sick leave'. BBC News (24 March 2010).

Buckton, K. E., O'riordan, M. L., Jacobs, P. A., Robinson, J. A., Hill, R., \& Evans, H. J. (1976). C - and Q - band polymorphisms in the chromosomes of three human populations. Annals of human genetics, 40(1), 99-112.

Caspersson, T., Zech, L., \& Johansson, C. (1970). Differential binding of alkilating fluorochromes in human chromosomes. Exp Cell Res, 60, 315-319.

Chiarelli, B., \& Lin, C. C. (1972). Comparison of fluorescence patterns in human and chimpanzee chromosomes. Genet Phaenen, 15, 103-106.

Décsey, K., Bellovits, O., \& Bujdoso, G. M. (2006). Human chromosomal polymorphism in Hungarian sample. Int J Hum Genet, 6(3), 177-183.

Eccles R. (2002a). Acute cooling of the body surface and the common cold. Rhinology, 40(3), 109-114.

Eccles R. (2002b). An explanation for the seasonality of acute upper respiratory tract viral infections. ActaOtolaryngol., 122(2), 183-91.

Eccles, R. (2005). Understanding the symptoms of the common cold and influenza. Lancet Infect Dis., 5(11), $718-25$.

Eccles, R., \& Veber, O. (2009). Common cold. Birkhauser, Basel, Boston, Berlin.

Fendrick, A. M., Monto, A. S., Nightengale, B., \& Sarnes, M. (2003). The economic burden of non-influenza-related viral respiratory tract infection in the United States. Archives of internal medicine, 163(4), 487-494.

Geraedts, J. P. M., \& Pearson, P. L. (1974). Fluorescent chromosome polymorphism: frequencies and segregation in a Dutch population. Clin Genet, 6, 247-257.

Grouchy, J. de., Turleau, C., Roubin, M., \& Chavin, C. F. (1973). Chromosomal evolution of man and the primates.In: Chromosome identification, technique and applications in biology and medicine. In $\mathrm{T}$. Caspersson, \& L. Zech (Eds.). Academic Press, New York, London.

Ibraimov, A. I, Akanov, A. A., Meymanaliev, T. S., Smailova, R. D., \& Baygazieva, G. D. (2014a). Chromosomal Q-heterochromatin and age in human population. J Mol Biol Res, 4(1), 1-9.

Ibraimov, A. I. (1993). The origin of modern humans: a cytogenetic model. Hum Evol, 8, 81-91.

Ibraimov, A. I. (2010). Chromosomal Q-heterochromatin regions in populations and human adaptation. In: MK Bhasin, C Susanne (Eds.): Anthropology Today: Trends and Scope of Human Biology. Delhi: Kamla- Raj Enterprises, pp. 225-250.

Ibraimov, A. I. (2011). Origin of modern humans: a cytogenetic model. Hum Evol, 26(1-2), 33-47.

Ibraimov, A. I. (2014). Chromosomal Q-heterochromatin and sex in human population. J Mol Biol Res, 4(1), $10-19$.

Ibraimov, A. I. (2015). Heterochromatin: The visible with many invisible effects. Global Journal of Medical Research (C), 15(3), 7-32 (Version 1.0).

Ibraimov, A. I., \& Kagagulova, G. O. (2006). Chromosomal Q-heterochromatin variability in neonates deceased during first year of age. Int J Hum Genet, 6(4), 281-285.

Ibraimov, A. I., \& Karagulova, G. O. (2006a). Chromosomal Q-heterochromatin regions in individuals of various age groups. Int. J. Hum. Genet., 6(3), 219-228.

Ibraimov, A. I., \& Mirrakhimov, M. M. (1982a). Human chromosomal polymorphism. III. Chromosomal Q-polymorphism in Mongoloids of northern Asia. Hum Genet, 62, 252-257.

Ibraimov, A. I., \& Mirrakhimov, M. M. (1982b). Human chromosomal polymorphism. IV. Chromosomal Q-polymorphism in Russians living in Kyrghyzia. Hum Genet, 62, 258-260.

Ibraimov, A. I., \& Mirrakhimov, M. M. (1982c). Human chromosomal polymorphism. V. Chromosomal Q-polymorphism in African populations. Hum Genet, 62, 261-265. 
Ibraimov, A. I., \& Mirrakhimov, M. M. (1985). Q-band polymorphism in the autosomes and the Y chromosome in human populations. In: Progress and Topics in Cytogenetics. The Y chromosome. Part A. Basic Characteristics of the Y chromosome. Ed. by A. A. Sandberg. Alan R. Liss Inc., New York, pp.213-287.

Ibraimov, A. I., \& Tabaldiev, S. K. (2007). Condensed chromatin, cell thermoregulation and human body heat conductivity. J. Hum. Ecol., 21(1), 1-22.

Ibraimov, A. I., Akanov, A. A., Meimanaliev, T. S., Sharipov, K. O., Smailova, R. D., \& Dosymbekova, R. (2014b). Human Chromosomal Q-heterochromatin Polymorphism and Its Relation to Body Heat Conductivity. Int J Genet, 6(1), 142-148.

Ibraimov, A. I., Akanov, A. A., Meymanaliev, T. S., Karakushukova, A. S., Kudrina, N. O., Sharipov, K. O., \& Smailova, R. D. (2013). Chromosomal Q-heterochromatin polymorphisms in 3 ethnic groups (Kazakhs, Russians and Uygurs) of Kazakhstan. Int. J. Genet, 5(1), 121-124.

Ibraimov, A. I., Akanov, A. A., Meymanaliev, T. S., Karakushukova, A. S., Kudrina, N. O., Sharipov K. O., \& Smailova, R. D. (2013). Chromosomal Q-heterochromatin polymorphisms in 3 ethnic groups (Kazakhs, Russians and Uygurs) of Kazakhstan. Int J Genet, 5(1), 121-124.

Ibraimov, A. I., Axenrod, E. I., Kurmanova, G. U., \& Turapov, D. A. (1991). Chromosomal Q-heterochromatin regions in the indigenous population of the northern part of West Siberia and new migrants. Cytobios, 67, 95-100.

Ibraimov, A. I., Karagulova, G. O., \& Kim, E. Y. (1997). Chromosomal Q-heterochromatin regions in indigenous populations of the Northern India. Ind J Hum Genet, 3, 7-81.

Ibraimov, A. I., Karagulova, G. O., \& Kim, E. Y. (2000). The relationship between the Y chromosome size and the amount of autosomal Q-heterochromatin in human populations. Cytobios, 102, 35-53.

Ibraimov, A. I., Kazakova, A. K., Moldotashev, I. K., Sultanmuratov, M. T., \& Abdyev, K. S. (2010). Variability of Human Body Heat Conductivity in Population I. Methodological and Theoretical Approaches. Journal of Human Ecology, 32(1), 1-22.

Ibraimov, A. I., Kurmanova, G. U., Ginsburg, E. K. h., Aksenovich, T. I., \& Axenrod, E. I. (1990). Chromosomal Q-heterochromatin regions in native highlanders of Pamir and Tien-Shan and in newcomers. Cytobios, 63, 71-82.

Ibraimov, A. I., Mirrakhimov, M. M., Axenrod, E. I., \& Kurmanova, G. U. (1986). Human chromosomal polymorphism. IX. Further data on the possible selective value of chromosomal Q-heterochromatin material. Hum Genet, 73, 151-156.

Ibraimov, A. I., Mirrakhimov, M. M., Nazarenko, S. A., Axenrod, E. I., \& Akbanova, G. A. (1982). Human chromosomal polymorphism. I. Chromosomal Q-polymorphism in Mongoloid populations of Central Asia. Hum Genet, 60, 1-7.

ISCN. (1978). An international system for human cytogenetic nomenclature. Report of the standing committee on human cytogenetic nomenclature. Cytogenet Cell Genet, 21, 313(1)-404(92).

Johnson, C., \& Eccles, R. (2005). Acute cooling of the feet and the onset of common cold symptoms. Family Practice, 22(6), 608-613.

Kalz, L., Kalz-Fuller, B., Hedge, S., \& Schwanitz, G. (2005). Polymorphism of Q-band heterochromatin; qualitative and quantitative analyses of features in 3 ethnic groups (Europeans, Indians, and Turks). Int J Hum Genet, 5(2), 153-163.

Lubs, H. A., Patil, S. R., Kimberling, W. J., Brown, J., Hecht, F., Gerald, P., \& Summitt, R. L. (1977). Racial differences in the frequency of Q- and C-chromosomal heteromorphism. Nature, 268, 631-632.

MacRae, F. (2009). Man flu is not a myth: Female hormones give women stronger immune systems. Daily Mail (Published 13 May 2009).

McKenzie, W. H., \& Lubs, H. A. (1975). Human Q and C chromosoma1 variations: distribution and incidence. Cytogenet Cell Genet, 14, 97-115.

Mourtzoukou, E. G. I., \& Falagas, M. E. (2007). Exposure to cold and respiratory tract infections. Int J Tuberc Lung Dis, 11(9), 938-943.

Muchmore, H. G., Parkinson, A. J., Humphries, J. E., Scott, E. N., McIntosh, D. A., Scott, L. V., ... \& Miles, J. A. (1981). Persistent parainfluenza virus shedding during isolation at the South Pole. Nature, 289, 187-189. 
Müller, H. J., Klinger, H. P., \& Glasser, M. (1975). Chromosome polymorphism in a human newborn population. II. Potentials of polymorphic chromosome variants for characterizing the idiograms of an individual. Cytogenet Cell Genet, 15, 239-255.

Paris Conference. (1971) and Supplement (1975). Standartization in human cytogenetics. Birth Defects: Original Article Series, XI, 1-84. The National Foundation, New York.

Pearson, P. L. (1973). Banding patterns chromosome polymorphism and primate evolution. Progress in Medical Genetics, 2, 174-197.

Pearson, P. L. (1977). The uniqueness of the human karyotype. In T. Caspersson \& L. Zech (Eds.), Chromosome identification: technique and applications in biology and medicine. New York, London: Academic Press.

Polderman, K. H. (2004). Application of therapeutic hypothermia in the intensive care unit.Opportunities and pitfalls of a promising treatment modality. Part 2. Practical aspects and side effects. Intensive care medicine, 30(5), 757-769.

Stanyon, R., Studer, M., Dragone, A., De Benedicts, G., \& Brancati, C. (1988). Population cytogenetics of Albanians in the province of Cosenza (Italy): frequency of Q and C band variants. Int J Anthropol, 3(1), 14-29.

Yamada, K., \& Hasegawa, T. (1978). Types and frequencies of Q-variant chromosomes in a Japanese population. Hum Genet, 44, 89-98.

Yoder Jr, H. W., Drury, L. N., \& Hopkins, S. R. (1977). Influence of environment on airsacculitis: effects of relative humidity and air temperature on broilers infected with Mycoplasma synoviae and infectious bronchitis. Avian diseases, 195-208.

\section{Copyrights}

Copyright for this article is retained by the author(s), with first publication rights granted to the journal.

This is an open-access article distributed under the terms and conditions of the Creative Commons Attribution license (http://creativecommons.org/licenses/by/3.0/). 